\title{
Steady state charge conduction through solution processed liquid crystalline lanthanide bisphthalocyanine films
}

\author{
Chandana Pal ${ }^{1}$, Isabelle Chambrier ${ }^{2}$ Andrew N. Cammidge ${ }^{2}$, A. K. Sharma ${ }^{3}$ and Asim K. Ray ${ }^{1}$ \\ ${ }^{1}$ Institute of Materials and Manufacturing, Brunel University London, Uxbridge, Middlesex UB8 \\ 3PH, UK, \\ ${ }^{2}$ School of Chemistry, University of East Anglia, Norwich NR4 7TJ, UK, \\ ${ }^{3}$ United States Air Force Research Laboratory, Space Vehicles Directorate, SE Kirtland AFB, NM \\ 87117 USA.
}

\begin{abstract}
In-plane electrical characteristics of non-peripherally octyl $\left(\mathrm{C}_{8} \mathrm{H}_{17}\right)$ and hexyl $\left(\mathrm{C}_{6} \mathrm{H}_{13}\right)$ substituted liquid crystalline (LC) double decker lanthanide bisphthalocyanine ( $\left.\mathrm{LnPc}_{2}\right)$ complexes with central metal ions lutetium ( $\mathrm{Lu})$, and gadolinium $(\mathrm{Gd})$ have been measured in thin film formulations on interdigitated gold $(\mathrm{Au})$ electrodes for the applied voltage $\left(V_{a}\right)$ range of $0 \leq V_{a} \leq 100 \mathrm{~V}$. The conduction mechanism is found to be Ohmic within the bias of $0 \leq V_{a} \leq 30 \mathrm{~V} \quad 0 \leq V_{\mathrm{a}} \leq 30 \mathrm{~V}$ while the bulk limited Poole-Frenkel mechanism is responsible for the higher bias. The compounds show individual characteristics depending on the central metal ions, substituent chain lengths and their mesophases. Values of $67.55 \mu \mathrm{Scm}^{-1}$ and $42.31 \mu \mathrm{Scm}^{-1}$ have been obtained. for room temperature in-plane Ohmic conductivity of as-deposited octyl lutetium $\left(\mathrm{C}_{8} \mathrm{LuPc}_{2}\right)$ and hexyl gadolinium $\left(\mathrm{C}_{6} \mathrm{GdPc}_{2}\right)$ films, respectively while $\mathrm{C}_{8} \mathrm{GdPc}_{2}$ films exhibit nearly two orders of magnitude smaller conductivity. On annealing at $80{ }^{\circ} \mathrm{C}$, Ohmic conductivities of $\mathrm{C}_{8} \mathrm{LuPc}_{2}$ and $\mathrm{C}_{8} \mathrm{GdPc}_{2}$ are found to have increased but the conductivity of $\mathrm{C}_{6} \mathrm{GdPc}_{2}$ decreases by more than one order of magnitude to $1.5 \mu \mathrm{Scm}^{-1}$. For physical interpretation of the charge transport behavior of these three molecules, their UV-visible optical absorption spectra have been studied in the solution and in as-deposited and annealed solid phases. It is believed that both orientational and positional reorganisations are responsible depending upon the size of the central ion and side chain length.
\end{abstract}

Key words: rare-earth atom, molecular organisations, Kasha model, Poole-Frenkel mechanism, activation energy 


\section{Introduction:}

Sandwich-type lanthanide bisphthalocyanine $\left(\mathrm{LnPc}_{2}\right)$ compounds, in which the large conjugated $\pi$ systems are held in proximity by the central rare-earth ions, are characterised by their free radical character, facilitating electron transfer from one molecule to another in the sold state phase [1]. These thermally stable compounds exhibit high intrinsic conductivities, small activation energy and large electronic affinity compared to those of monophthalocyanines [2]. These compounds have a wide range applications for developing organic field-effect transistors [3], environmental sensors [4], biosensors [5], optical switches [6], photovoltaic cells [7], and cancer treatment to name a few [8]. The UV absorption spectra of newly synthesised lanthanide clampshell type diphthalocyaninate compounds bearing 24-crown-8 linking fragment complexes show solvent induced panchromatic absorption in polar solvents [9]. Quasi Langmuir-Shajer highly ordered thin films of mixed sandwich (phthalocyaninato) (porphyrinato) europium(III) double-decker complex on indium tin oxide electrodes was investigated as an enzymatic free electrochemical sensor to detect dopamine. The sensor shows linear amperometric response between $8 \mu \mathrm{M}$ and $100 \mu \mathrm{M}$ dopamine with a low detection limit of $4.8 \mu \mathrm{M}$, but with good selectivity and sensitivity [10]. Similarly, environmental sensors have been developed using quasi Langmuir-Shajer films of mixed (phthalocyaninato) (porphyrinato) europium triple-decker complexes as sensitive layer for ammonia $\left(\mathrm{NH}_{3}\right)$ and nitrogen dioxide $\left(\mathrm{NO}_{2}\right)$ with low detection limits of $1 \mathrm{ppm}$ and $0.4 \mathrm{ppm}$, respectively [11].

Steady state current-voltage characteristics were measured on $50 \mathrm{~nm}$ thick sublimed films of heavyfraction rare-earth-element bisphthalocyanines on aluminum electrodes in planar configurations within the temperature range between $77 \mathrm{~K}$ and $300 \mathrm{~K}$. Charge hopping between localised states was found to be dominant for temperatures below $162 \mathrm{~K}$ while high temperature excitation to a singlet state below the conduction edge [12]. Unsubstituted lutetium bis-phthalocyanine ( $\left.\mathrm{LuPc}_{2}\right)$ is believed to be the first intrinsic molecular semiconductor with room temperature steady state conductivity lying in the range between $10^{-4} \mathrm{Sm}^{-1}$ and $10 \mathrm{Sm}^{-1}$ at room temperature with an activation energy of $0.1 \mathrm{eV}$ [13]. This high value of the conductivity is due to the high density carriers in the order of 
$10^{23} \mathrm{~m}^{-3}$ induced by the small energy gap of $0.4 \pm 0.1 \mathrm{eV}$ as found from the ultraviolet photoemission spectroscopic measurements on thermally evaporated $25 \mathrm{~nm}$ thick $\mathrm{LnPc}_{2}$ films [14]. The bond distance and the bond angles are sensitive to the central metal atom and the functional groups. The coordination number of these lanthanide ions is typically 8 or 9 . The self-assembling ability of the phthalocyanines in the liquid crystalline mesophases contributes to advanced charge transport properties [15]. Studies have been carried out on thermal properties on liquid crystalline $\operatorname{LnPc}_{2}$ compounds peripherally substituted with alkoxy of different chain lengths. All compounds exhibit a hexagonal columnar mesophase over the temperature range between $313 \mathrm{~K}$ and $553 \mathrm{~K}$. The dependence of the transition temperature is found to be more pronounced for the chain lengths than lanthanide ions [16]. Substituted Lu bisphthalocyanine complexes with eight long alkyl chains exhibit ordered liquid crystalline mesomorphic properties over temperature range between $100 \mathrm{~K}$ and $500 \mathrm{~K}$. Values of the macroscopic electrical conductivity are small in the order of $4.0 \times 10^{-10} \mathrm{Sm}^{-1}$, $2.0 \times 10^{-9} \mathrm{Sm}^{-1}$, and $2.0 \times 10^{-12} \mathrm{Sm}^{-1}$, for isotropic, liquid crystalline and solid mesophases, respectively. The carriers hopping between the columns is believed to be responsible for improved conductivity by three orders of magnitude in the liquid crystalline phase in comparison to the solid phase [17]. Rare-earth bisphthalocyaninate double decker europium(Eu), gadolinium (Gd) and terbium $(\mathrm{Tb})$ compounds substituted with sixteen alkythio chains $\left[\left(\mathrm{C}_{\mathrm{n}} \mathrm{S}\right)_{8} \mathrm{Pc}\right]_{2} \mathrm{M}$ have been investigated for their mesophase dependent charge transport properties for $\mathrm{n}=8,10,12,14,16,18$. In their unique pseudo-hexagonal phases, the charge mobility of $\left[\left(\mathrm{C}_{12} \mathrm{~S}\right)_{8} \mathrm{Pc}\right]_{2} \mathrm{Lu}$ is found to be $70 m^{2} V^{-1} s^{-1}$, a value larger than one in hexagonal columnar phase. However, hexadecaalkyl substitutions on peripheral positions produce intracolumnar charge mobility varying between $0.15 \mathrm{~cm}^{2} V^{-1} \mathrm{~s}^{-1}$ and $0.3 \mathrm{~cm}^{2} V^{-1} \mathrm{~s}^{-1}[18]$.

Thioalkythio substituted cerium bisphthalocyanine $\left[\left(\mathrm{C}_{n} \mathrm{H}_{2 n+1} \mathrm{~S}\right){ }_{8} \mathrm{Pc}\right] \mathrm{Ce}(8 \geq \mathrm{n} \geq 18)$ compounds show hexagonal columnar phase before melting to isotropic liquids. Values of enthalpy varies between $16.6 \mathrm{kJmol}^{-1}$ for $\mathrm{n}=8$ to $3.9 \mathrm{kJmol}^{-1}$ for $\mathrm{n}=14$. This decrease in enthalpy implies that the molecular disorder of the supercooled sample is less important than the freshly recrystallised sample. 
A value of $7.0 \times 10^{-3} \mathrm{~cm}^{2} \mathrm{~V}^{-1} \mathrm{~s}^{-1}$ is obtained for the field and temperature independent hole mobility from the time of flight measurement at $107^{\circ} \mathrm{C}$ on a $4.26 \mathrm{~mm}$ thick sample with the longest chain $\left[\left(\mathrm{C}_{18} \mathrm{H}_{37} \mathrm{~S}\right)_{8} \mathrm{Pc}\right] \mathrm{Ce}$ in the hexagonal columnar phase [19]. Approximately 40nm thick spincoated films of alkyl-substituted dysprosium (Dy) phthalocyanine molecules $\left[\left(\mathrm{C}_{6} \mathrm{~S}\right)_{8} \mathrm{Pc}\right]_{2}$ Dy showed an increase in room temperature Ohmic conductivity by two orders of magnitude from $6.57 \times 10^{-8} \mathrm{Sm}^{-1}$ to $6.42 \times 10^{-6} \mathrm{Sm}^{-1}$ as the sample was annealed at the liquid crystalline temperature of $350 \mathrm{~K}$, implying the formation of thermally induced ordered film [20]. Variable hopping conduction mechanism is found to be responsible for steady state charge transport through the spin coated films of bis(double-decker lutetium(III) phthalocyanine) $\left(\mathrm{Lu}_{2} \mathrm{Pc}_{4}\right)$ on interdigitated gold electrode between temperature range between $50 \mathrm{~K}$ and $290 \mathrm{~K}$.. The characteristic hopping distance and barrier height are reported to be $8.98 \mathrm{~nm}$ and $0.027 \mathrm{eV}$ with room temperature conductivity of $5.7 \times 10^{-5} \mathrm{Sm}^{-1}[21]$. The Ohmic conductivity of $5 \mathrm{~nm}$ thick thermally deposited bis(phthalocyaninato)terbium(III) ( $\left.\mathrm{TbPc}_{2}\right)$ under high vacuum conditions is found to be $0.032 \mathrm{~S} \mathrm{~m}^{-1}$ at $303 \mathrm{~K}$ with the value of $0.158 \mathrm{eV}$ for the temperature independent activation energy implying the thermal excitation of carriers from a continuous density of deep trap states [22].

This paper reports the results of experimental investigations into steady state charge conduction through the thin films of non-peripherally octyl $\left(\mathrm{C}_{8} \mathrm{H}_{17}\right)$ and hexyl $\left(\mathrm{C}_{6} \mathrm{H}_{13}\right)$ substituted bisphthalocyanine compounds with central metal lutetium (Lu), and gadolinium (Gd) ions with their chemical structures shown in Figure 1(a). These molecules are soluble in the most common solvents and therefore the spreading solution may be spin coated on interdigitated gold electrodes. Experimental results have been analysed in order to identify the relevant mechanism.

\section{Experimental:}

The $>99.9 \%$ pure phthalocyanines Viz. $\mathrm{C}_{8} \operatorname{LuPc}_{2}(\mathbf{1}), \mathrm{C}_{8} \mathrm{GdPc}_{2}(\mathbf{2}), \mathrm{C}_{6} \mathrm{GdPc}_{2}$ (3) in Figure 1 were supplied from the University of East Anglia in powder form.

Differential scanning calorimetric (DSC) curves were recorded for as-prepared bulk material $8 \mathrm{GdPc}_{2}$ over a temperature range between $-50^{\circ} \mathrm{C}$ to $200^{\circ} \mathrm{C}$. using a Linkham THM600 hot stage, and with a TA Instruments DSC 10 instrument coupled to a TA200 workstation. 
Spin-coating was used for the fabrication of thin films of the solution processible bisphthalocyanine (Pc) compounds. About $50 \mu \mathrm{l}$ of the $5 \mathrm{mgml}^{-1}$ spreading solution in chloroform (99.9\% anhydrous) was dispersed on ultrasonically clean quartz/interdigitated gold coated glass substrate according to requirement and left for 30 seconds. The dispersed solution was allowed to spin at $2000 \mathrm{rpm}$ for 30 seconds. Prior to the preparation of the film, the glass surface was cleaned in an ultrasonic bath (Ultrawave U50, UK). The substrates were sonicated in distilled water of resistivity $18.2 \mathrm{M} \Omega$, acetone, and isopropyl alcohol, in sequence for 15 minutes each. The cleaned substrates were then dried with nitrogen gas before film deposition. A KW-4A spin coater from Chemat Technology Inc., USA was used to produce thin films. The coated sample was dried for at least 4 hours inside vacuum desiccator.

The optical properties of compounds $\mathbf{1 , 2}$ and 3 in both solution and solid phase were studied using UV-Vis spectroscopy. In the case of solution phase absorption spectra, the compound was dissolved in an appropriate solvent and kept in a standard $1 \mathrm{~cm}$ quartz cell. A reference $1 \mathrm{~cm}$ quartz cell filled with the solvent was used simultaneously throughout the experiments to avoid the effect of background absorbance. To monitor solid film spectra a spin-coated sample on quartz slide was used with a reference quartz slide.

The as-deposited spun thin films of the bisphthalocyanines were heated to $80^{\circ} \mathrm{C}$ in an oven under atmospheric pressure to investigate the molecular organisations and its effect on charge transport properties. The samples were left at the high temperature for 1 hour, followed by slow cooling to room temperature at $5^{\circ} \mathrm{C} \mathrm{min}^{-1}$. This annealing temperature was chosen to be just above the crystalmesophase melting temperature, according to the phase transition exhibited by DSC plots of the three compounds 1, 2 and 3 in the supplementary material S1, S2 and S3 respectively.

The in-plane steady state charge transport studies of the spun films of the three compounds were performed using a two-probe method on interdigitated gold electrodes in the dark and under vacuum conditions $\left(\geq 10^{4} \mathrm{~Pa}\right)$. The applied voltage $\left(V_{\mathrm{a}}\right)$ was swept from 0 to $100 \mathrm{~V}$ in the dark at a scan rate of $0.5 \mathrm{Vs}^{1}$. Figure $1 \mathrm{~b}$ is the sketch of the enlarged view of the electrodes. The channel length $(L)$, width $(W)$, and number of fingers $(N)$ of the interdigitated electrodes were measured as $45 \mu \mathrm{m}, 0.716$ $\mathrm{cm}$ and 24 , respectively using a microscope objective of $\times 5$ magnification. The in-plane currentvoltage $\left[I-\left(V_{\mathrm{a}}\right)\right]$ characteristics of the phthalocyanines were studied using a microprocessor controlled Keithley 617 electrometer and data were analysed using a LABVIEW programme. 
Samples were kept in high vacuum of $\geq 10^{-4}$ mbar in an Oxford instrument cryostat. Contacts between the cryostat pin and electrodes were made with silver paste. The temperature was controlled and measured by an Oxford instrument ITC 601 temperature controller. A Zygo NewView 5000 interferometer with white laser was used for thickness measurement. Measurements were repeated on five different areas of the film and an average value of the thickness was used for analysis.

\section{Results and discussions:}

\subsection{DSC and Optical absorption of the compounds 1, 2 and 3}

Transition temperatures for phase changes have been well defined by DSC curves in Figure2. The compounds are thermally stable and the decomposition temperature is above $250^{\circ} \mathrm{C}$ independent of substituent or central metal. The compounds $\mathbf{1 , 2 , 3}$ undergo the crystallization at temperature $45.9^{\circ} \mathrm{C}$, $45.06^{\circ} \mathrm{C}$, and $-18.79^{\circ} \mathrm{C}$, respectively. At temperature above, but close to the temperature $\mathrm{T}_{\mathrm{m}}$ of transition of columnar to liquid crystal phase $\mathrm{T}_{\mathrm{m}}, 61^{\circ} \mathrm{C}, 64^{\circ} \mathrm{C}$ and $66^{\circ} \mathrm{C}$ for the compounds $\mathbf{1 , 2 , 3}$, respectively start melting and shows transition from crystal into the columnar liquid crystal mesophase. The columnar arrangements are maintained until the next mesophase-mesophase transitions above $100^{\circ} \mathrm{C}$. The columnar liquid crystal phase temperature are found to be $61^{\circ} \mathrm{C}, 64^{\circ} \mathrm{C}$ and $66^{\circ} \mathrm{C}$ respectively

A sharp Q-band arising from the $0.01 \mathrm{mgml}^{-1}$ neutral solution of compound $\mathbf{1}\left(\mathrm{C}_{8} \mathrm{LuPc}_{2}\right)$ in chloroform appears at $714 \mathrm{~nm}\left(\mathrm{Q}_{\mathrm{y}}\right.$ band) in the absorption spectrum (a) in Figure 3(I). An additional band of comparatively lower intensity is situated at $653 \mathrm{~nm}\left(\mathrm{Q}_{\mathrm{x}}\right.$ band). The peaks are sharp in this spectrum as the screening effect of the solvent prevents the molecular aggregations. The small shoulder at $473 \mathrm{~nm}$ is a characteristic band for the neutral rare-earth bisphthalocyanines attributable to the radical nature of the molecules. The $\mathrm{Q}_{\mathrm{y}}$-band for the compound in an as-deposited spun film on quartz substrate in Figure 3(I)(b) was found to be broad at $718 \mathrm{~nm}$, indicating this small redshift of the band with respect to Figure 3(I)(a). According to Kasha molecular exciton model, the redshift of the optical band is caused by the slipped stacking arrangements or J-aggregations which causes interactions between the molecular transition dipoles situated parallel to the molecular profile [23]. The spectrum of the annealed film of compound $\mathbf{1}$ is also included in Figure 3(I)(c). The Q band positions upon annealing show significant differences from the as-deposited film. There is a further redshift of the $\mathrm{Q}_{\mathrm{y}}$ and $\mathrm{Q}_{\mathrm{x}}$ bands now situated at 730 and $655 \mathrm{~nm}$, from the as-deposited solid phase spectrum at $718 \mathrm{~nm}$ and $653 \mathrm{~nm}$. Similar observations of broadening and red shift of Q band have been made in the UV-visible absorption spectra of the annealed spin-coated films of bis[octakis(hexylthio)phthalocyaninato] rare-earth metal complexes. The kind of redshift may be 
attributed to the long-range staggered slipped stacking arrangements of the transition dipoles in form of stacks [24].

Compound $2\left(\mathrm{C}_{8} \mathrm{GdPc}_{2}\right)$ in a solution phase of $0.01 \mathrm{mgml}^{-1}$ chloroform also shows two Q bands at $724 \mathrm{~nm}$ and $640 \mathrm{~nm}$ in Figure 3(II)(a). Similar to compound 1, the Q band positions in the spectrum 3(II)(b) for the solid thin film are broadened and the $\mathrm{Q}_{\mathrm{y}}$ and $\mathrm{Q}_{\mathrm{x}}$ bands are red shifted to $728 \mathrm{~nm}$ and $643 \mathrm{~nm}$ respectively, in relation to the solution spectrum. As before, this is due to the formation of Jaggregation of the transition dipoles. A small band characterising the radical form of the molecule is present at $473 \mathrm{~nm}$. These positions are comparable to those obtained for the octa-2,2,3,3tetrafluoropropoxy $\mathrm{GdPc}_{2}$ complex [25]. The stacking arrangements of transition dipoles after annealing in the discotic LC mesophase lead to significant red shifts of the $\mathrm{Q}_{\mathrm{y}}$ and $\mathrm{Q}_{\mathrm{x}}$ bands to 750 from $724 \mathrm{~nm}$ and $648 \mathrm{~nm}$ from $640 \mathrm{~nm}$ respectively, in the spectrum 3(II) (c).

No significant difference was noticed between the solution phase spectra of compound $\mathbf{3}$ gadolinium derivative with the octyl substitutions in Figure 3(II)(a). The chain length of alkyl groups does not affect the main electronic transitions in monomeric form in the solution phase as the distance of the side chain from the molecule centre is relatively large. The comparatively higher wavelength/low energy optical absorption of the solution phase hexyl and octyl substituted gadolinium phthalocyanine derivatives compared to the octyl substituted Lu-derivative have revealed that the larger ionic radius of the central metal ion leads to a weaker $\pi-\pi$ interaction. However, the $\mathrm{Q}_{\mathrm{y}}$ and $\mathrm{Q}_{\mathrm{x}}$ bands of thin film solid spectra were found at $721 \mathrm{~nm}$ and $637 \mathrm{~nm}$ in comparison to the 728 and $643 \mathrm{~nm}$ bands of compound 2. Unlike the redshifts in other two Pcs compounds $\mathbf{1}$ and $\mathbf{2}$, the blueshift of the Q bands in compound 3 with respect to the solution phase Q bands may be related to the differences in molecular arrangements in the solid phase. According to the Kasha model the blue shifted exciton is usually observed when there is $\pi-\pi$ interaction between the transition dipoles in the direction perpendicular to the Pc ring. The Q bands of the compound 3 film in discotic LC phase are further blue shifted from $721 \mathrm{~nm}$ and $637 \mathrm{~nm}$ to $715 \mathrm{~nm}$ and $625 \mathrm{~nm}$, respectively, most probably due to long range face-toface stacking arrangements of the monomers. The blueshifts in the as-deposited and LC phases are comparable to those of tetra-substituted nickel phthalocyanines. These blueshifts are believed to reflect the enhancement of $\pi-\pi$ interactions inside the double-decker subunits [26]. However, the radical band was situated at $473 \mathrm{~nm}$ irrespective of metal ion, side chain, or single crystal structure. The variations in the absorption maxima of the main visible region bands for the solution, as deposited, and annealed film of compound 1, 2 and $\mathbf{3}$ are summarised in Table 1. 


\subsection{Steady State conductivity of compounds 1,2 and 3}

The in-plane current-voltage $\left[I-\left(V_{\mathrm{a}}\right)\right]$ curves of the as-deposited compounds $\mathbf{1 , 2 , 3}$ on sweeping the voltage from 0 to $100 \mathrm{~V}$ have been shown in Figure 4 on sweeping the voltage from 0 to $100 \mathrm{~V}$. Bisphthalocyanine films are believed to have formed Ohmic contacts with gold electrodes [27]. The characteristic features of all three curves are similar, containing two regimes of conduction for $0 \mathrm{~V} \leq V_{\mathrm{a}} \leq 30 \mathrm{~V}$ and $30 \mathrm{~V} \leq V_{\mathrm{a}} \leq 100 \mathrm{~V}$. The conductivity is found to be dependent upon both the substituents and central metal ions. Compound $\mathbf{1}$ shows higher in plane conductivity than the relatively large in size Gd-derivatives compounds $\mathbf{2}$ and $\mathbf{3}$. This observation is agreement with results reported earlier for lutetium bispthalocyanine [28]. In fact, being the smallest rare-earth atom, lutetium containing compounds show assembly of the highest carrier density of the material from its homologues. Consequently, the intrinsic conductivities of Lu-compounds are highest among the rare earth bisphthalocyanines [29].

For further analysis, the characteristics have been plotted in Figure 5 on logarithmic scales. The slope of the current-voltages logarithm plot was 0.96 in Figure 5a obeying the Ohm's law of $I \propto V_{\mathrm{a}}$. over the entire voltage range of $0 \mathrm{~V}$ to $100 \mathrm{~V}$. The value of in-plane conductivity $\left(\sigma_{\mathrm{x}}\right)$ is found to be $67.55 \mu \mathrm{Scm}^{-1}$ for the as-deposited film of compound 1 from the intercept of the Figure 5a using the following mathematical equation in the form [30]

$$
\sigma_{\mathrm{x}}=\frac{I}{V_{a}} \frac{L(N-1)}{w d}
$$

where, the number of fingers $(\mathrm{N})$ in the interdigitated electrode is 24 , the length of electrodes $(L)$ is $45 \mu \mathrm{m}$, and the thickness of the film of compound 1 is $74 \pm 15 \mathrm{~nm}$.

The annealed film of compound $\mathbf{1}$ is annealed at $80^{\circ} \mathrm{C}$, two different mechanisms of conduction are observed in Figure 5a. Region I of $0 \mathrm{~V} \leq V_{\mathrm{a}} \leq 30 \mathrm{~V}$ and Region II of $30 \mathrm{~V} \leq V_{\mathrm{a}} \leq 100 \mathrm{~V}$ : Ohmic conduction is dominant in the low voltage range of $0 \mathrm{~V} \leq V_{\mathrm{a}} \leq 30 \mathrm{~V}$. The slope of the linear plot for an annealed device in the Figure 5a was found to be 1.01. Slightly higher Ohmic conductivity of $\sigma_{\mathrm{x}}=$ $79.51 \mu \mathrm{Scm}^{-1}$ is estimated for the annealed film with discotic LC structure. DC conductivities of solution-processed $150 \mathrm{~nm}$ thick films of peripherally bis[tetrakis(alkylthio) phthalocyaninato]lutetium(III) bisphthalocyanine compunds $\left[\left(\mathrm{C}_{n} \mathrm{H}_{2 n+1} \mathrm{~S}\right)_{4} \mathrm{Pc}\right]_{2} \mathrm{Lu}(\mathrm{III})(n=6,8,10$, $12,16)$ on interdigitated electrodes were obtained in the range of $10^{-2} \mu \mathrm{Scm}^{-1}$ and $10 \mu \mathrm{Scm}^{-1}$ in the solid phase. These values are in the same order of magnitude but numerically smaller [31]. 
Region II of $30 \mathrm{~V} \leq V_{\mathrm{a}} \leq 100 \mathrm{~V}$ : For the annealed device of compound 1, the slope of the $\log I$ versus $\log V_{\mathrm{a}}$ plot is 1.3 in Figure $5 \mathrm{a}$ in the voltage range of $30 \mathrm{~V} \leq V_{\mathrm{a}} \leq 100 \mathrm{~V}$ which is steeper than that in the Ohmic region with the slope of 1.01. As the annealing of the films were carried out in an oxygen $\left(\mathrm{O}_{2}\right)$ environment, it is possible that the adsorbed $\mathrm{O}_{2}$ ions in the grain boundary act as defect states and produce a columbic potential barrier and trap the charge. Under high applied potential, the barrier is reduced making it easier for the holes to vacate the trap by thermal emission. The decreasing barrier height between the conduction and valence bands under electric field is responsible for the increased conduction from $30 \mathrm{~V}$ to $100 \mathrm{~V}$ by detrapping the charge carriers [32]. Similar behavior of Ohmic and non-Ohmic conduction has been reported for low and high bias voltages, respectively has been reported for spin coated films of tetrasubstituted lutetium bis-phthalocyanines on indium tin oxide substrates [33].

For compound 2, Figure 5b shows two distinct slopes of trap-free charge conduction in the range of $0 \leq V_{\mathrm{a}} \leq 30 \mathrm{~V}$ and non-Ohmic in the range of $30 \mathrm{~V} \leq V_{\mathrm{a}} \leq 100 \mathrm{~V}$ in the logarithmic $\left[I-\left(V_{\mathrm{a}}\right)\right]$ characteristics at room temperature. The Ohmic conductivity at room temperature was calculated for the $60 \pm 15 \mathrm{~nm}$ thick film from the region I, as $0.40 \mu \mathrm{Scm}^{-1}$. On annealing, the conductivity was found to be increased to $\sigma_{\mathrm{x}}=0.91 \mu \mathrm{cm}^{-1}$. The slight enhancement of the Ohmic conductivity in the annealed film with respect to the as-deposited one can be attributed to the directional anisotropy of the Pc monomers in the LC mesophase. The observation in optical absorption suggested existence of staggered slipped stacking arrangements or J-aggregates of the Pc monomers in the spun film of both compounds $\mathbf{1}$ and 2. On annealing, the more ordered long-range leads to enhancement of the conductivity of the material in comparison to the as-deposited one. This supports the red-shift of the Qy optical band in the annealed films of both compounds $\mathbf{1}$ and $\mathbf{2}$ with respect to the as-deposited one [34].

Similar plots in Figure 5c for as-deposited and annealed thin films of compound $\mathbf{3}$ also exhibited Ohmic characteristics in the range of $0 \mathrm{~V} \leq V_{\mathrm{a}} \leq 30 \mathrm{~V}$ with slope of nearly 1 in Region I.. The Ohmic conductivity of the as-deposited film was estimated to be $\sigma_{\mathrm{x}}=42.3 \mu \mathrm{Scm}^{-1}$ from Equation (1). The thickness of the film was taken as $80 \pm 15 \mathrm{~nm}$ for the conductivity calculation. Unlike compounds 1 and 2 , the in-plane conductivity $\sigma_{\mathrm{x}}$ of the annealed film of compound 3 is found to have decreased to $1.5 \mu \mathrm{Scm}^{-1}$ by about one order of magnitude. The interpretation of the further blue-shift of the $\mathrm{Q}_{\mathrm{y}}$ band of UV-Vis spectra on annealing suggests the formation of more ordered H-aggregated or faceto-face arrangements of the Pc units in the LC phase. The stacking of Pc units is actually expected to enhance the conductivity of the material through long range $\pi-\pi$ interactions. The best result of electrical conduction is expected when the Pc units are aligned to the direction of charge flow which 
is parallel to the electrodes in case of in-plane conduction. The conductivity measured perpendicular to the sample plane of spin-coated thin films of octa(13,17-dioxanonacosane-15-sulfanyl)-substituted mesomorphic luteum is found to decrease by four orders of magnitude from $1.9 \times 10^{-6} \mathrm{Sm}^{-1}$ to $6.1 \times 10^{-10} \mathrm{Sm}^{-1}$ on annealing to $140^{\circ} \mathrm{C}$ for $3 \mathrm{~h}$ due to formation of a staggered slipped stacking structure [35]. Similar stacking of aggregated molecules in different directions is therefore believed to be responsible for the decrease of film conductivity on annealing for compound 3. It may be possible that the long-chain substitution inhibits the charge flow inside the aromatic core of the Pcs. The higher in plane conductivities in the hexyl substituted Gd-derivative with respect to the octyl one can be related to this circumstance. On the basis of recent hole transfer integral calculations, it has been shown that the influence of Gd-atoms is relatively small in intermolecular charge transfer while electronic coupling depends largely on the overlap of $\pi$-orbitals of the phthalocyanine [36]

For the physical interpretation of non-linear behaviors of annealed compound 1 and both as-deposited and annealed for compounds 2 and 3 in Figure 4, plots of $\ln \left(\mathrm{I} / \mathrm{V}_{\mathrm{a}}\right)$ versus $\sqrt{V_{a}}$ in Figure 6 respectively are found to be linear in consistent with bulk-limited Poole-Frenkel conduction [37]:

$$
\mathrm{I}=\frac{V_{\mathrm{a}}}{L} \exp \left[-q\left(\frac{\beta_{P F} \sqrt{V_{a}}-\Phi_{t}}{k_{B} T}\right)\right]
$$

$\beta_{\mathrm{PF}}$ is Poole- Frenkel field lowering coefficient equal to $\beta_{\mathrm{PF}} / \sqrt{\mathrm{L}} . \mathrm{k}_{\mathrm{B}}$ is the Boltzmann constant; $\mathrm{T}$ is the temperature. $\Phi_{t}$ is zero field potential barrier height coefficient.

For compound 2, it is obvious from the Figure $6 \mathrm{~b}$ that the slope of the $\ln \left(\mathrm{I} / \mathrm{V}_{\mathrm{a}}\right)$ versus $\sqrt{V_{a}}$ for annealed films is steeper, with slope (0.71), than the as-deposited films with slope $(0.40)$ indicating the rate of increasing current per unit applied voltage is higher in the annealed film. The higher field lowering factor $\beta_{\mathrm{PF}} \sqrt{ } \mathrm{V}_{\mathrm{a}}$ in the annealed film may imply the release of trapped charges in an increased proportion [38]. Similarly, values of 0.18 and 0.30 have been estimated for the as-deposited and annealed films, respectively for compound $\mathbf{3}$.

Further measurements of $I-\left(V_{\mathrm{a}}\right)$ characteristics have been undertaken over temperature range from $302 \mathrm{~K}-360 \mathrm{~K}$ for annealed films of compound $\mathbf{1}$ and for both the as-deposited and annealed device for compound 2, and 3. The $I\left(V_{\mathrm{a}}\right)$ characteristics on logarithmic scale for the annealed film of compound $\mathbf{1}$ is shown in Figure 7a. As expected for organic semiconductors, the conductivity was found to have increased because the trapped charge carriers are released on thermal excitation and contribute to the charge transport. A decrease in the gradient of slopes in the region $30 \mathrm{~V} \leq V_{\mathrm{a}} \leq 100 \mathrm{~V}$ 
was calculated in Figure 6 a from 1.3 at $302 \mathrm{~K}$ to 1.1 at $360 \mathrm{~K}$. This is due to fact that the higher thermal energy causes detrapping of charge carriers easier and the conduction mechanism approaches towards Ohmic [39]. In order to determine the activation energy $\Delta E$ of the film, the Arrhenius plots of $\left(I \propto e^{-\frac{\Delta E}{k_{B} T}}\right)$ were shown in $7 \mathrm{~b}$ in terms of the logarithm of current versus inverse temperature for four different bias voltages of $35 \mathrm{~V}, 60 \mathrm{~V}, 80 \mathrm{~V}$ and $100 \mathrm{~V}$ corresponding to the Poole-Frenkel region and the slopes $\Delta E=k_{B} \frac{\mathrm{d} \ln I}{\mathrm{~d}\left(\frac{1}{T}\right)}$ of the linear plots in Figure $6 \mathrm{~b}$ have been plotted in Figure $7 \mathrm{c}$ against the square root of voltage $V_{a}$.

The field lowering coefficient $\beta_{P F}$ and zero field potential barrier height $\phi_{t}$ are related to the activation energy $\Delta E$ through the equation in the following form:

$$
\Delta E=\left(\beta_{P F} \sqrt{V_{a}}-\phi_{t}\right)
$$

Values of $5.65 \times 10^{-4} \mathrm{eVcm}^{1 / 2} \mathrm{~V}^{-1 / 2}$ and $0.33 \mathrm{eV}$ have been calculated for the barrier lowering coefficient $\beta_{P F}$ zero field potential barrier height coefficient $\left(\phi_{t}\right)$, respectively for annealed films of Compound 1 from the slope and intercept of $\Delta \mathrm{E}$ against $V_{\mathrm{a}}^{\frac{1}{2}}$ plot in Figure $7 \mathrm{c}$. The value of $\beta_{P F}$ agrees well with the estimated value of $3.54 \times 10^{-4} \mathrm{eVcm}^{1 / 2} \mathrm{~V}^{-1 / 2}$ using the equation $\beta_{P F}=\sqrt{\frac{q^{3}}{\pi \varepsilon_{0} \varepsilon_{r}}}$ and using the value of $\varepsilon_{0} \varepsilon_{r}=3.54 \times 10^{-11} \mathrm{Fm}^{-1}[40]$.

Figure $8 \mathrm{a}$ and $8 \mathrm{~b}$ display the increasing current with temperature rise, in the logarithmic $I-\left(V_{a}\right)$ characteristics of compound $\mathbf{2}$ for as-deposited and annealed films, respectively. In the Poole-Frenkel region, slopes of $\ln I$ versus $1 / T$ plots at different voltage were employed to evaluate the field lowering parameters in both as-deposited and annealed films (Figure 8c). As can be seen from Figure 8d, the value of $\Delta \mathrm{E}$ decreases with the square root of voltage in both cases as the higher electric field detrapping the charge carriers. The intercept of the plots or the zero field columbic barriers was found to be increased from $0.82 \mathrm{eV}$ to $0.99 \mathrm{eV}$ on annealing due to thermal excitation of the carriers from the deep trap states [41]. The corresponding $\beta_{\mathrm{PF}}$ values were estimated be $6.74 \times 10^{-4} \mathrm{eVV}^{-1 / 2} \mathrm{~cm}^{1 / 2}$ and $43.12 \times 10^{-4} \mathrm{eVV}^{1 / 2} \mathrm{~cm}^{-1 / 2}$ for as-deposited and annealed films, respectively. The 6.5 times increase in $\beta_{\mathrm{PF}}$ in the well-ordered LC phase explains the higher current in the annealed film of $\mathrm{C}_{8} \mathrm{GdPc}_{2}$ in comparison to the as deposited one.

The current voltage characteristics are presented in Figure $9 \mathrm{a}$ and $9 \mathrm{~b}$ for the as-deposited and annealed films of compound 3 over the same temperature range. As expected, the barrier potential increased to $0.88 \mathrm{eV}$ in the annealed film from $0.63 \mathrm{eV}$ of the as deposited one resulting from the 
decrease in currents at different voltage from $0 \mathrm{~V}$ to $100 \mathrm{~V}$ as shown earlier in Figure $6 \mathrm{c}$. The $\beta_{\mathrm{PF}}$ values were estimated to be $18.25 \times 10^{-4} \mathrm{eVV}^{-1 / 2} \mathrm{~cm}^{1 / 2}$ and $8.35 \times 10^{-4} \mathrm{eVV}^{-1 / 2} \mathrm{~cm}^{1 / 22}$ for the as-deposited and annealed films, respectively.

It is interesting to note that values of $\beta_{P F}$ are positive for all compounds. The physical interpretation of these positive values of may be obtained by examining their dependence on the Gaussian density of energy states of width $\partial$ and the dimensionless parameter defining the positional disorder $\Gamma$ through the following form:

$$
\beta_{P F}=0.78 \sqrt{\frac{q R}{\sigma}}\left[(\partial / k T)^{3 / 2}-\Gamma\right]
$$

where $\mathrm{R}$ is the intersite spacing parameter [42]. It is obvious from Equation (4) that the positional order $\Gamma$ is small in comparison with energy states of width $\partial$ implying the liquid crystalline films are well structured.

\subsection{Summary and Concluding remarks:}

The results of DSC, UV-Vis and electrical characterisations of newly synthesised liquid crystalline $\mathrm{C}_{8} \mathrm{GdPc}_{2}, \mathrm{C}_{8} \mathrm{LuPc}_{2}$, and $\mathrm{C}_{6} \mathrm{GdPc}_{2}$ are summarized in Table I and II. The alignments of the side chains were found to have an important role in the molecular arrangements of the compounds. Characteristic liquid crystalline phases of these molecules have been identified from differential scanning calorimetry supported by observation from the UV-visible absorption, showing crystal-columnar mesophase and columnar mesophase-isotropic liquid transitions. The combined interpretation of UVVis spectra and the electrical characteristics suggest the formation of the J-aggregates of the Pc units within the as-deposited spun films in compound $\mathbf{1}$ and $\mathbf{2}$ but $\mathrm{H}$-aggregates for compound $\mathbf{3}$. On annealing, the more ordered J aggregated stacking of Pc units in preferable directional anisotropy to the charge flow enhance the conductivity of the material in comparison to the as-deposited one. The different directional anisotropic property of the H-aggregated molecules with respect to the charge flow direction on the substrate in compound $\mathbf{3}$ is likely to be the reason for the decrease of film conductivity on annealing. The in-plane conductivity value of the $\mathrm{C}_{8} \mathrm{LuPc}_{2}$, was found to be two orders of magnitude higher than the larger in size Gd-derivative with same chain length substituents due to the size effect of the central metal ion. A two order of magnitude higher value for hexyl substituted Gd-derivative with respect to the octyl one was obsevered. The annealing promoted the alignment of the Pc units in more organized way influencing the optical and electrical properties of 
the films. Increase of Ohmic conductivity was noticed in case of octyl substituted lutetium and gadolinium phthalocyanines.

\section{Acknowledgements}

This work is sponsored by the Air Force Office of Scientific Research, Air Force Material Command, USAF, under grant no. FA8655-13-1-3018.

\section{References:}

1. Bouvet M., Gaudillat P., Suisse J. M ., J. Porphyr. Phthalocyanines 2013; 17(8-9) 628-635.

2. Turek P., Petit P., André J-J., Simon, J. Even R., Boudgema B., Guillaud G., Maitrot M., J. Am. Chem. Soc., 1987, 109, 5119-5122.

3. Chaure N. B., Sosa-Sanchez J. L., Cammidge A. N., Cook M. J. Ray A. K., Org. electron. 2010; 11(3),434-438

4. Wannebroucq A., Ouedraogo S., Meunier-Prest R., Suisse J. M., Bayo M. Bouvet M., Sens. Actuator B-Chem. 2018; 258, 657-664

5. M. L. Rodriguez-Mendez, M. Gay, J. A. de Saja, J. Porphyr. Phthalocyanines, 2009, 13, 1159.

6. Liu M. O., Tai C. H. Hu A. T. and Wei T. H., J. Organomet. Chem. 2004; 689(12), 21382143.

7. Videlot C., Fichou D. and Garnier F, Synth. Met.1999; 102(1-3), 1052-1052.

8. Teo R. D., Termini J. and Gray H. B. J. Med. Chem. 2016, 59(13), 6012-6024.

9. Birin K. P. Poddubnaya, A. I., Isanbaeva E. V., Gorbunova Y. G. and Tsivadze A. Y. J. Porphyr. Phthalocyanines 2017,21(4-6) Special Issue: SI, 406-415.

10. Cheng Q. Q., Wang H. Y. Wu Y. L., Zhao S., Kong X., Chen Y. L. and Jiang J. Z. J. Porphyr. Phthalocyanines 2017 21(12), 796-802.

11. Abdullah K., Chen Y. L. and Jiang J. Z., J. Porphyr. Phthalocyanines 2017,21(12), 893-899

12. Exley J., Ray A. K. Ahmet M. T. and Silver J., J. Mater. Sci.-Mater. Electron. 1994, 5(3), 180 184.

13. Andre J. J. ,Holczer K., Petit P., Riou M. T., Clarisse C., Even R., Fourmigue M. and Simon J.. Chem. Phys. Lett. 1985, 115(4-5), 463-466.

14. Murdey R., Bouvet M., Sumimoto M., Sakaki S., Sato, N. Synth. Met. 2009, 159(1516) Pages: 1677-1681

15. Binnemans, K and Gorller-Walrand, C., Chem. Rev.2002; 102(6), 2303-2345 
16. Binnemans K., Sleven J., De Feyter S., De Schryver F. C., Donnio B. and Guillon D., Chem. Mat. 2003, 15(20); 3930-3938

17. Z. Belarbi, C. Sirlin, J. Simon, J. J. Andre, J. Phys. Chem., 1989, 93(24), 8105- 8110. Bouvet M. and Simon J. J., Chem. Phys. Lett. 1990, 172(3-4), 299-302

18. Ban K., Nishizawa K., Ohta K., de Craats A. M. V., Warman J. M., Yamamoto I. and Shirai, H., J. Mater. Chem., 2001, 11(2), 321-331

19. . Nekelson, H. Monobe, M. Shiro, and Y. Shimizu, J. Mater. Chem., 2007, 17, 2607-2615.

20. T. Basova, A. G. Gurek, V. Ahsen, A. K. Ray, Org. Electron, 2007, 8(6), 784-790.

21. Altindal A., Abdurrahmanoglu S., Bulut M. and Bekaroglu O., Synth. Met. 2005, 150(2) Pages: $181-187$

22. R. Murdey, K. Katoh, M. Yamashita, N. Sato, Thin Solid Films, 2018, 646, 17-20.

23. M. Kasha, H. R. Rawls, and M. A. El-Bayoumi, Pure Appl. Chem., 1965, 11, 371-392.

24. Gurek A. G., Basova T., Luneau D., Lebrun C., Kol'tsov E. Hassan A. K. and Ahsen V., Inorg. Chem 2006, 45(4), 1667-1676.

25. Orman E. B., Koca A., Ozkaya A. R. Gurol I., Durmus M., and Ahsen, V., J. Electrochem. Soc. 2014, 161(6), H422-H429

26. Korostei Y. S., Pushkarev V. E., Tolbin A. Y., Dzuban A. V., Chernyak A. V., Konev D. V., Medvedeva T. O., Talantsev A. D., Sanina N. A. and Tomilova L. G., Dyes Pigment. 2019, 170 Article Number: UNSP 107648

27. Jones R., Krier A and Davidson K., Thin Solid Films 1997, 298(1-2), 228-236

28. Maitrot M., Guillaud G., Boudjema B., Andre J. J., Strzelecka H., Simon J. Even R., Chem. Phys. Lett.1987; 133(1) 59-62

29. Smykalla L., Shukrynau P. and Hietschold M., J. Phys. Chem. C 2012, 116(14), 80088013.

30. Pistoia G, Zane D, Zhang Y., J. Electrochem. Soc. 1995, 142(8), 2551

31. D. Atilla, N. Kilinc, F. Yuksel, A.G. Gürek, Z. Z. Öztürk, and Ahsena, V. Synth. Met., 2009, 159(1-2), $13-21$.

32. Hill R. M. , Philos Mag, 1971, 23(181), 59-86.

33. Bilgicli A.T., Gunsel A., Kandaz M., Altindal A. and Comert H. J. Porphyr. Phthalocyanines 2016, 20(8-11) , 1065-1074. 
34. Bilgicli A.T., Gunsel A., Kandaz M. Altindal A . and Comert H., J. Organomet. Chem., 2015, 785, 112-121

35. T.V. Basova, E. Kol'tsov, A. K. Hassan, A. K . Ray, A.G. Gürek, and V. Ahsen, Mater. Chem. and Phys., 2006, 96 (1), 129-135.

36. Kratochvilova I., Sebera J., Paruzel B., Pfleger J, Toman P., Maregova E., Havlova S., Hubik, P., Buryi M., Vrnata M, Slota R., Zakrzyk M., Lancok J., Novotny M., Synth. Met. 2018;236, 68-78

37. Gould R. D., Coord. Chem. Rev, 1996, 156 237-274

38. Bushby R. J., Evans S. D., Lozman O. R., McNeill A and Movaghar B., J. Mater. Chem. 2001, 11(8), 1982-1984.

39. Pisula W., Zorn M., Chang J. Y., Mullen K. and Zentel R., Macromol. Rapid Commun., 2009,30(14) Special Issue: SI 1179-1202

40. Gould R. D. and Shafai T. S., Thin Solid Films, 2000, 373(1-2), 89-93

41. Murdey R., Katoh K. Yamashita M. and Sato N. Thin Solid Films, 2018, 646, 17-20.

42. Hertel D., Bässler H., Scherf U. and Hörhold H. H. J. Chem. Phys., 1999, 110(18) 9214-9222. 
Figure 1: (a) Bis[1,4,8,11,15,18,22,25-octakis(alkyl) phthalocyanine molecule, $\mathrm{C}_{\mathrm{n}} \mathrm{MPc}_{2}$, For molecule 1, $\mathrm{M}=\mathrm{Lu}, \mathrm{R}=\mathrm{C}_{8} \mathrm{H}_{17}$; molecule 2, $\mathrm{M}=\mathrm{Gd}, \mathrm{R}=\mathrm{C}_{8} \mathrm{H}_{17}$; molecule 3, $\mathrm{M}=\mathrm{Gd}$, $\mathrm{R}=\mathrm{C}_{6} \mathrm{H}_{13}$; (b) schematic diagram of electrode systems

Figure 2: Differential scanning calorimetric curves for (a) compound 1, (b) compound 2 and (c) compound $\mathbf{3}$ for heating and cooling cycles.

Figure 3: UV-Vis spectra of (I) compound 1 (II) compound 2 and (III ) compound 3 in (a) 0.01 $\mathrm{mgml}^{-1}$ chloroform solution of (dotted line), (b) as-deposited thin film (solid line), (c) annealed film (dash line).

Figure 4: Current-Voltage $\left.I-\left(V_{\mathrm{a}}\right)\right]$ characteristics on logarithmic linear scales for as-deposited films of compound (a) 1 (b) 2 and (c) 3 at room temperature in dark at a scan rate of 0.5 $\mathrm{V} / \mathrm{sec}$

Figure 5: Current-Voltage $\left[I-\left(V_{\mathrm{a}}\right)\right]$ characteristics on logarithmic scales for as-deposited and annealed films of (a) compound 1, (b) compound $\mathbf{2}$ and ( c) compound $\mathbf{3}$ at room temperature in dark at a scan rate of $0.5 \mathrm{~V} / \mathrm{sec}$.

Figure 6: $\quad \ln \left(I / V_{\mathrm{a}}\right)$ versus square root of voltage in the range of $30 \mathrm{~V} \leq V_{\mathrm{a}} \leq 100 \mathrm{~V}$ for (a) annealed films compound 1, as-deposited and annealed compounds (b) 2 and (c) 3.

Figure 7: (a) Current-voltage characteristics for compound 1 at different temperature in the range of $302 \mathrm{~K}-360 \mathrm{~K}$ for as-deposited film, (b) logarithm of current versus temperature inverse at different voltages at different temperature in the range of temperature $302 \mathrm{~K}-360 \mathrm{~K}$, (c) $\Delta E$ versus square root of voltage plot for as-deposited film of compound $\mathbf{1}$

Figure 8: (a) Current-voltage characteristics at different temperature in the range of $302 \mathrm{~K}-360 \mathrm{~K}$ for (a) as-deposited and (b) annealed film of compound 2, (c) Logarithm of current versus temperature inverse at different voltages, (d) $\Delta E$ versus square root of voltage plot for as-deposited and annealed films of compound $\mathbf{2}$.

Figure 9: (a) Current-voltage characteristics at different temperature in the range of 302K-360K for (a) as-deposited and (b) annealed film of compound 3, (c) Logarithm of current versus temperature inverse at different, (d) $\Delta E$ versus square root of voltage plot for asdeposited and annealed films of compound 3. 
Table I: Positions of bands of optical absorption spectra of compound 1, 2 and 3.

\begin{tabular}{|c|c|c|c|c|c|c|c|c|c|}
\hline \multirow{2}{*}{ Compound } & \multicolumn{3}{|c|}{ Solution in chloroform } & \multicolumn{3}{|c|}{ As-deposited Film } & \multicolumn{3}{|c|}{ Annealed Film } \\
\hline & $\mathbf{Q}_{\mathbf{y}}$ & $\mathbf{Q}_{\mathbf{x}}$ & $\begin{array}{c}\text { Radical } \\
\text { band }\end{array}$ & $\mathbf{Q}_{\mathbf{y}}$ & $\mathbf{Q}_{\mathbf{x}}$ & $\begin{array}{c}\text { Radical } \\
\text { band }\end{array}$ & $\mathbf{Q}_{\mathbf{y}}$ & $\mathbf{Q}_{\mathbf{x}}$ & $\begin{array}{c}\text { Radical } \\
\text { band }\end{array}$ \\
\hline 1 & 714 & 653 & 473 & 718 & 652 & 473 & 730 & 655 & 473 \\
\hline 2 & 724 & 640 & 473 & 728 & 643 & 473 & 750 & 648 & 473 \\
\hline 3 & 724 & 640 & 473 & 721 & 637 & 473 & 715 & 625 & 473 \\
\hline
\end{tabular}

Table II: Comparative study of the electrical characteristics of the three compounds 1, 2 and 3 in the voltage range $30 \mathrm{~V} \leq V_{\mathrm{a}} \leq 100 \mathrm{~V}$ at $302 \mathrm{~K}$

\begin{tabular}{|c|c|c|c|c|c|c|c|c|c|}
\hline \multirow{3}{*}{ Compound } & \multirow{3}{*}{$\begin{array}{l}\text { Thickness } \\
( \pm 15 \mathrm{~nm})\end{array}$} & \multicolumn{2}{|c|}{$\begin{array}{c}\text { Ohmic Conduction } \\
\sigma_{\mathrm{x}}\left(\times 10^{-5} \mathrm{Scm}^{-1}\right)\end{array}$} & \multicolumn{6}{|c|}{ Poole-Frenkel Conduction } \\
\hline & & \multirow[t]{2}{*}{$\begin{array}{c}\text { As- } \\
\text { deposited }\end{array}$} & \multirow[t]{2}{*}{ Annealed } & \multicolumn{3}{|c|}{ As- deposited } & \multicolumn{3}{|c|}{ Annealed } \\
\hline & & & & $\begin{array}{c}\boldsymbol{B}_{\mathrm{PF}} \\
\left(\times 10^{-3}\right. \\
\left.\mathbf{e V V}^{-1 / 2}\right)\end{array}$ & $\begin{array}{c}\beta_{\mathrm{PF}} \\
\left(\times 10^{-4}\right. \\
\mathrm{eVV}^{-} \\
\left.{ }^{1 / 2} \mathbf{c m}^{1 / 2}\right)\end{array}$ & $\begin{array}{c}\Phi_{\mathrm{t}} \\
(\mathrm{eV})\end{array}$ & $\begin{array}{c}\boldsymbol{\beta}_{\mathrm{PF}} \\
\left(\times 10^{-}\right. \\
3 \\
\mathbf{e V V ^ { - }} \\
\mathbf{1 / 2})\end{array}$ & $\begin{array}{c}\boldsymbol{\beta}_{\mathrm{PF}} \\
\left(\times 10^{-4}\right. \\
\mathbf{e V V ^ { - }} \\
\left.{ }^{1 / 2} \mathbf{c m}^{1 / 2}\right)\end{array}$ & $\begin{array}{c}\Phi_{\mathrm{t}} \\
(\mathrm{eV})\end{array}$ \\
\hline 1 & 74 & 6.75 & 7.95 & ----- & ---- & ----- & 8.42 & 5.65 & 0.33 \\
\hline 2 & 60 & 0.04 & 0.09 & 9.95 & 6.74 & 0.82 & 64.30 & 43.12 & 0.99 \\
\hline 3 & 80 & 4.23 & 0.15 & 27.22 & 18.25 & 0.63 & 12.4 & 8.35 & 0.88 \\
\hline
\end{tabular}



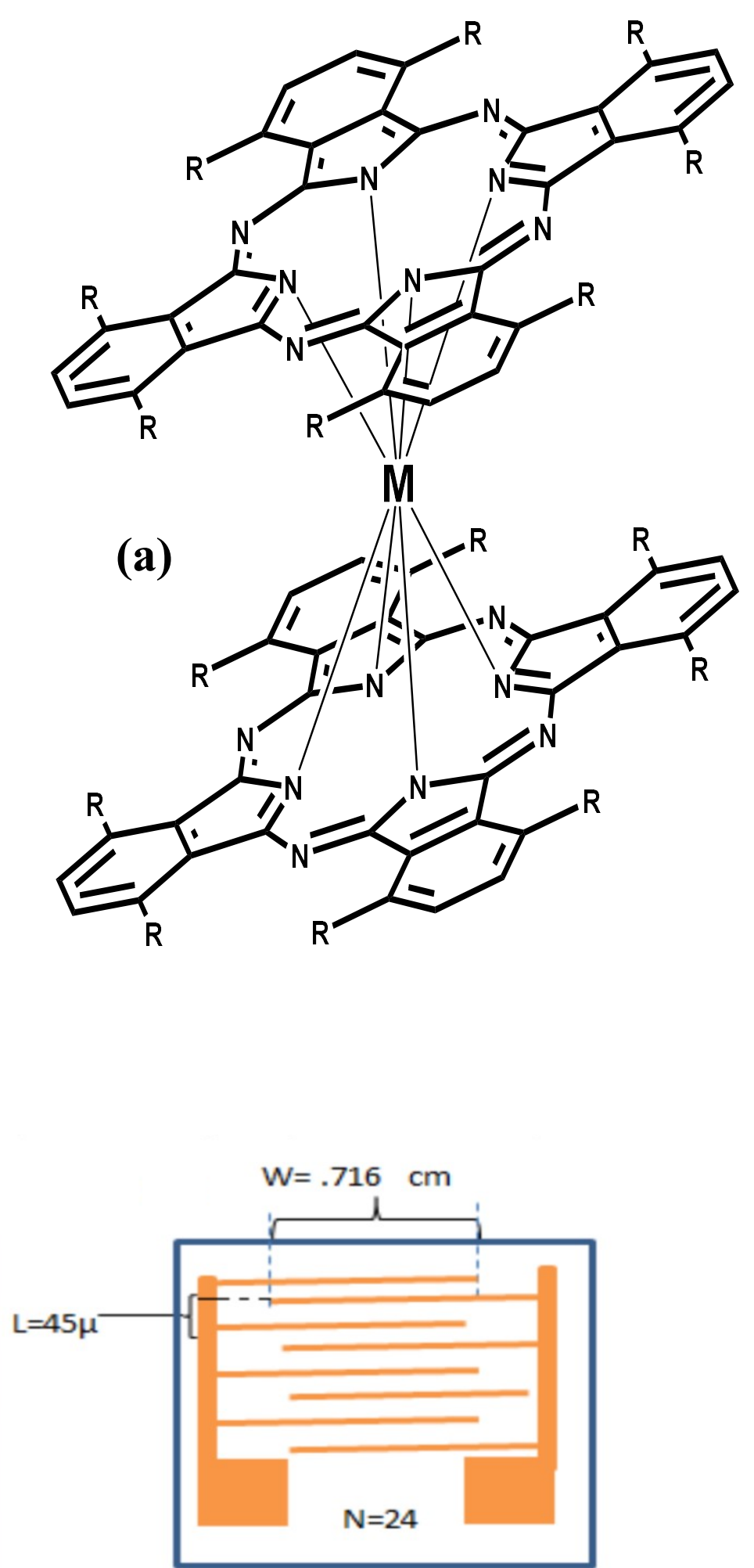

(b)

Figure 1: (a) Bis[1,4,8,11,15,18,22,25-octakis(alkyl) phthalocyanine molecule, $\mathrm{C}_{\mathrm{n}} \mathrm{MPc}_{2}$, For molecule 1, $\mathrm{M}=\mathrm{Lu}, \mathrm{R}=\mathrm{C}_{8} \mathrm{H}_{17}$; molecule 2, $\mathrm{M}=\mathrm{Gd}, \mathrm{R}=\mathrm{C}_{8} \mathrm{H}_{17}$; molecule 3, $\mathrm{M}=\mathrm{Gd}$, $\mathrm{R}=\mathrm{C}_{6} \mathrm{H}_{13}$; (b) schematic diagram of electrode systems 

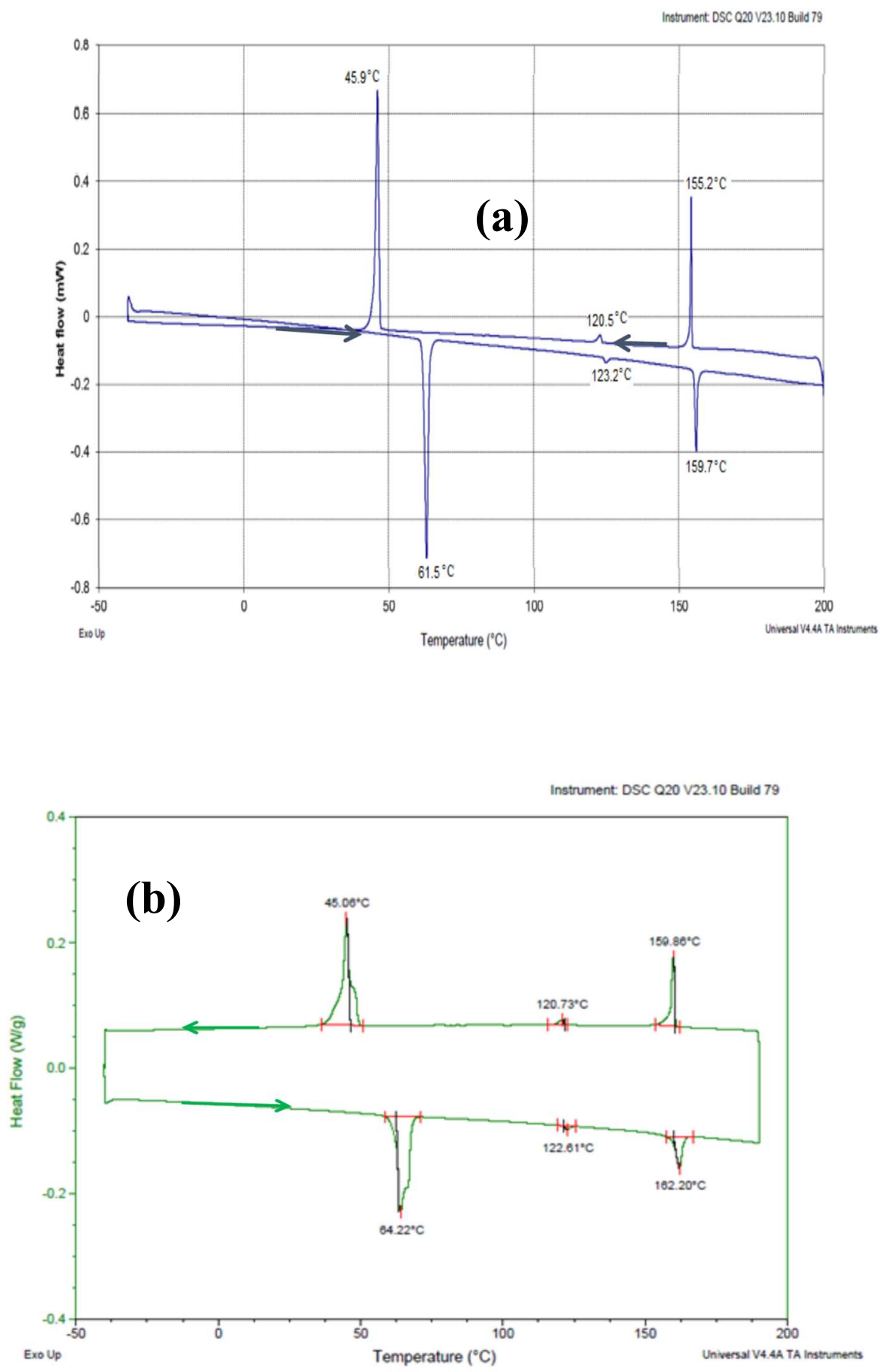


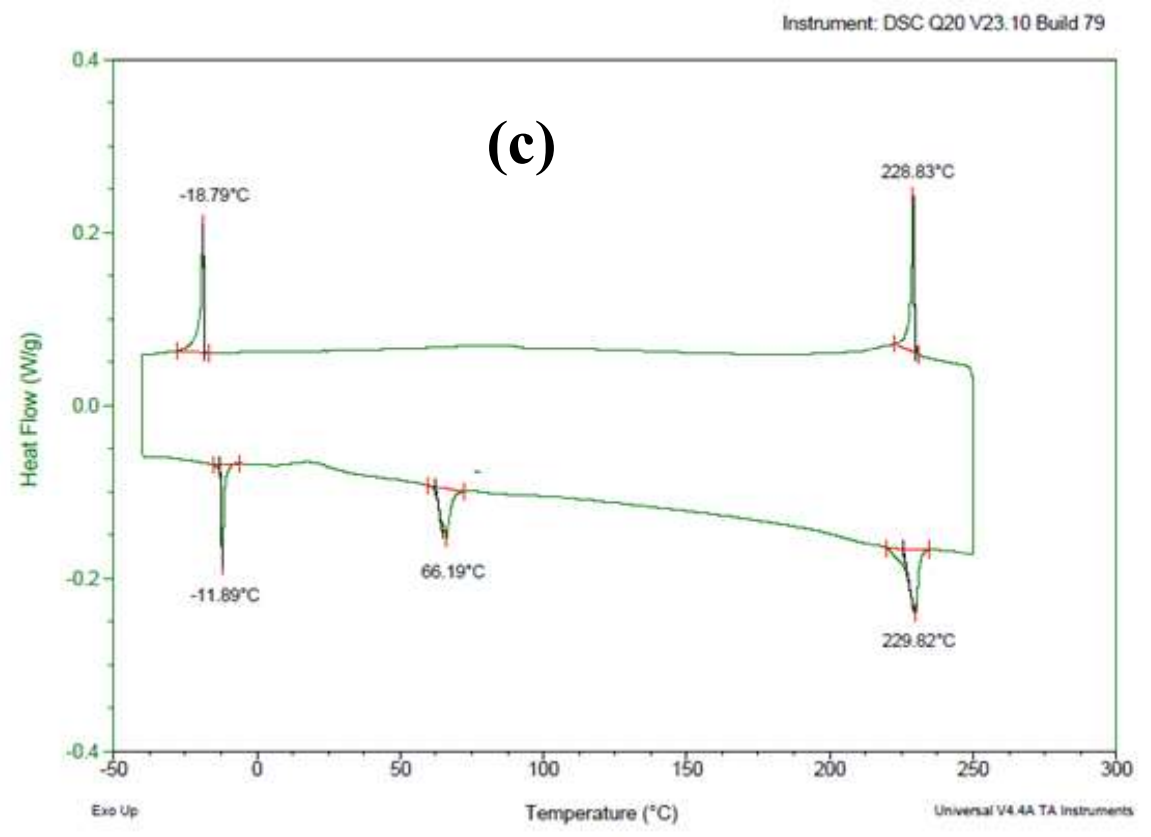

Figure 2: Differential scanning calorimetric curves for (a) compound 1, (b) compound 2 and (c) compound $\mathbf{3}$ for heating and cooling cycles 
(I)

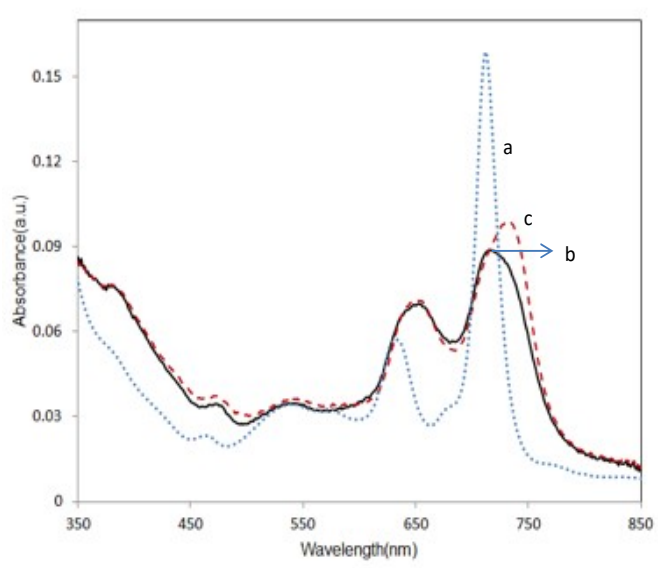

(II)

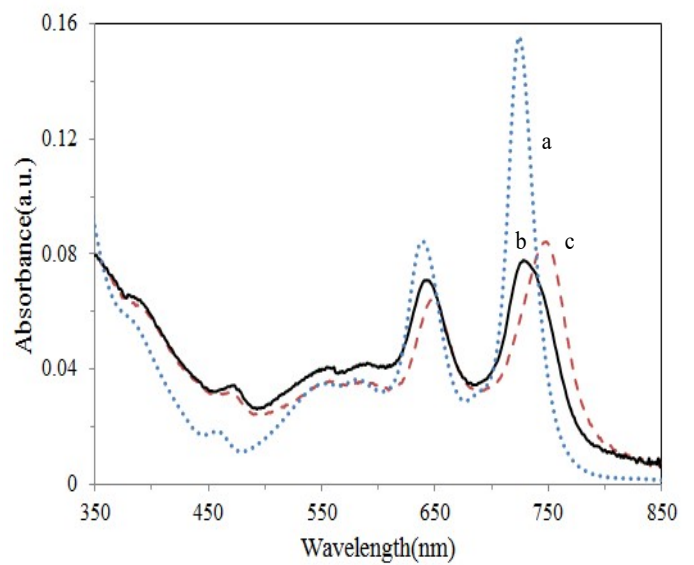

(III)

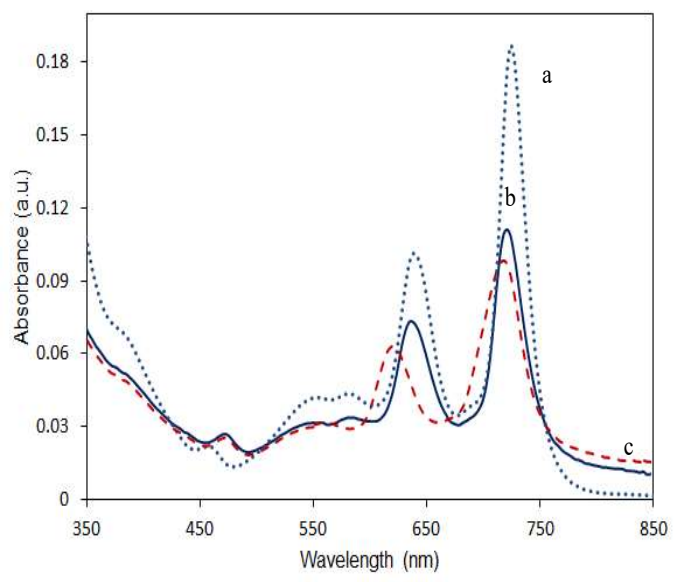

Figure 3: UV-Vis spectra of (I) compound 1 (II) compound 2 and (III ) compound 3 in (a) 0.01 $\mathrm{mgml}^{-1}$ chloroform solution of (dotted line), (b) as-deposited thin film (solid line), (c) annealed film (dash line). 


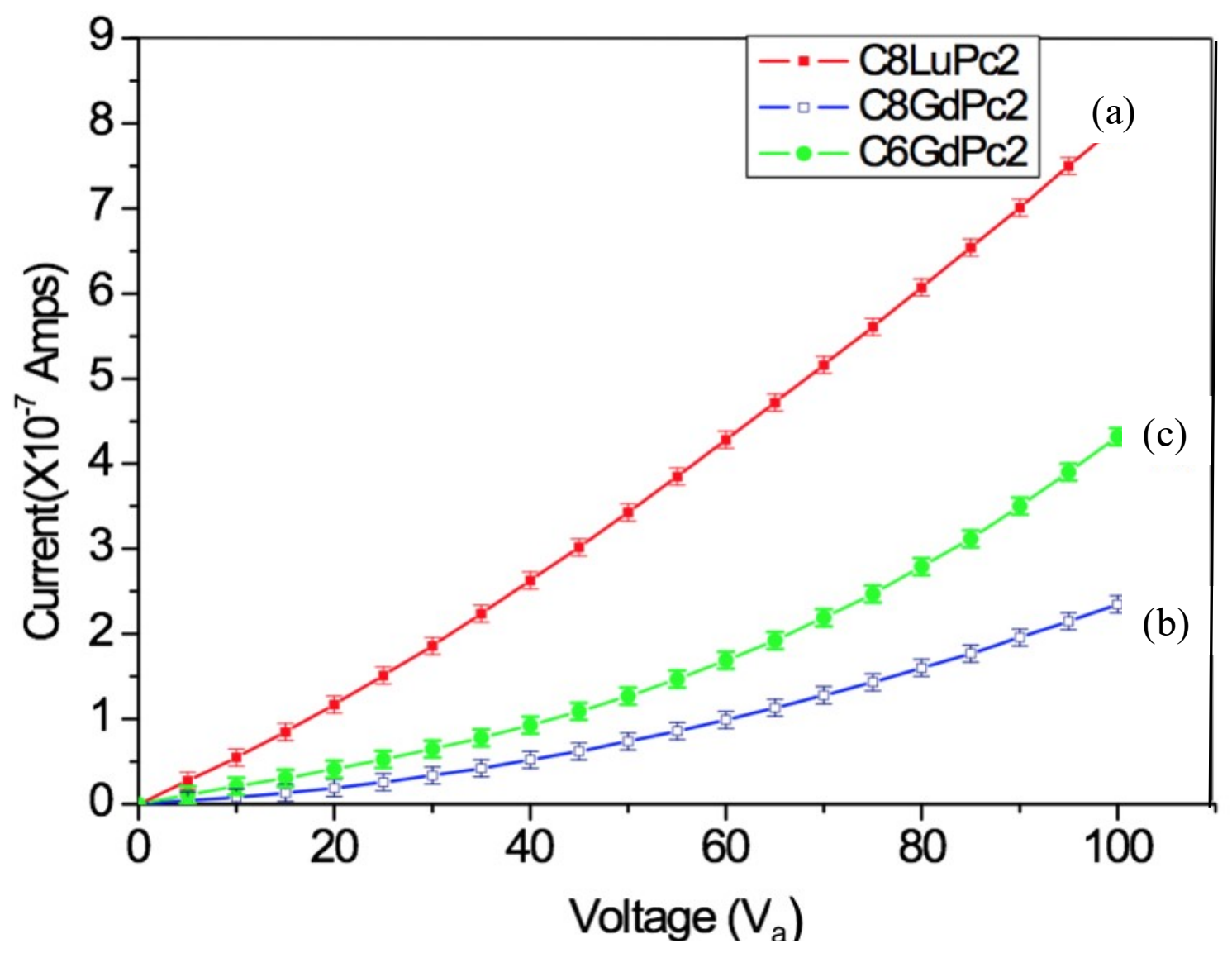

Figure 4: Current-Voltage $\left.I-\left(V_{\mathrm{a}}\right)\right]$ characteristics on logarithmic linear scales for as-deposited films of compound (a) 1 (b) 2 and (c) 3 at room temperature in dark at a scan rate of 0.5 $\mathrm{V} / \mathrm{sec}$ 
(a)

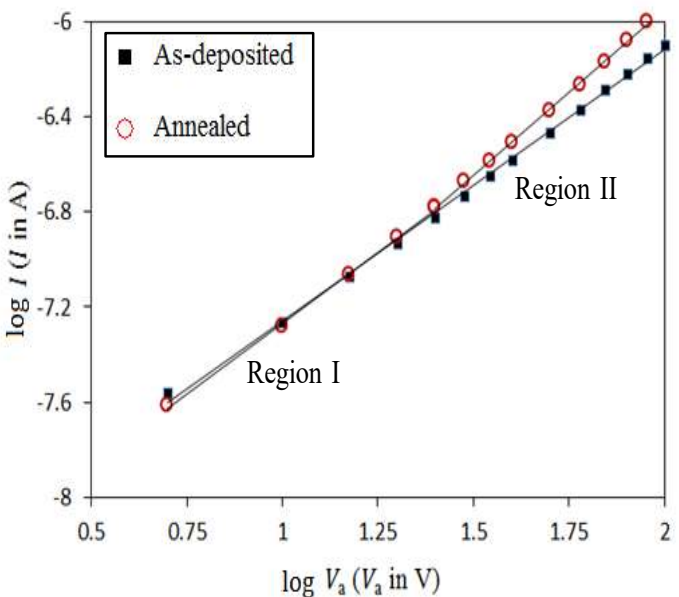

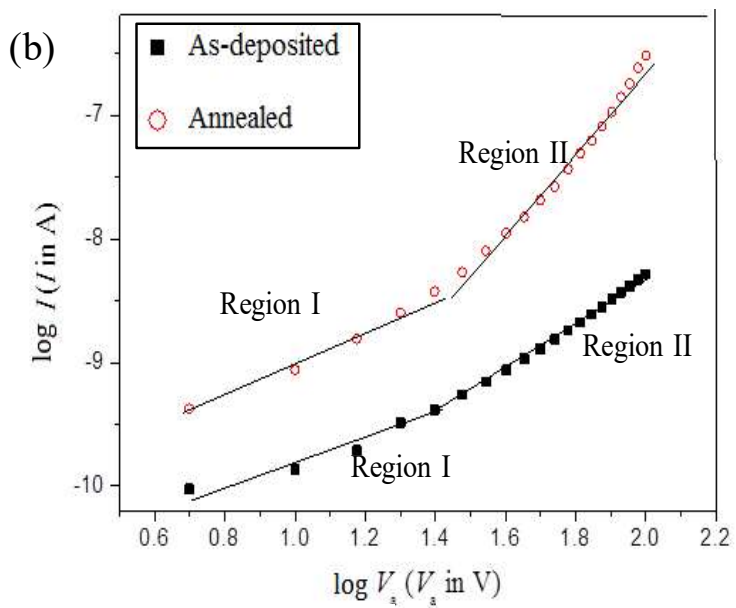

(c)

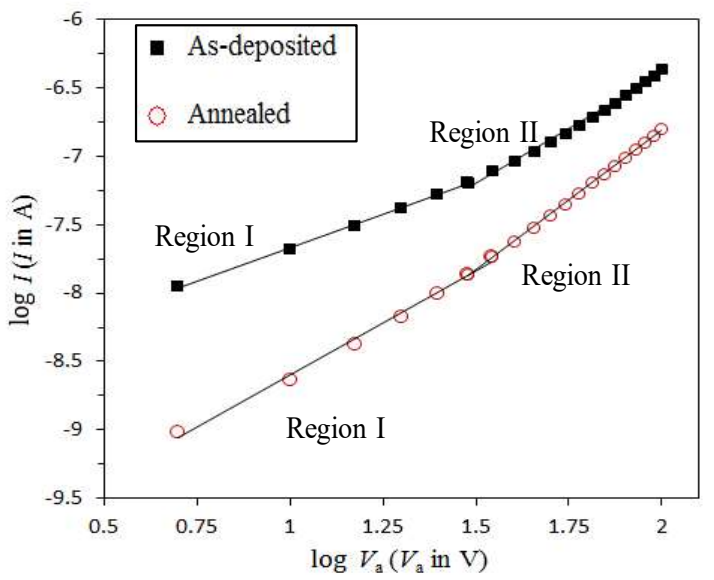

Figure 5: Current-Voltage $\left[I-\left(V_{\mathrm{a}}\right)\right]$ characteristics on logarithmic scales for as-deposited and annealed films of (a) compound 1, (b) compound $\mathbf{2}$ and ( c) compound $\mathbf{3}$ at room temperature in dark at a scan rate of $0.5 \mathrm{~V} / \mathrm{sec}$. 
(a)

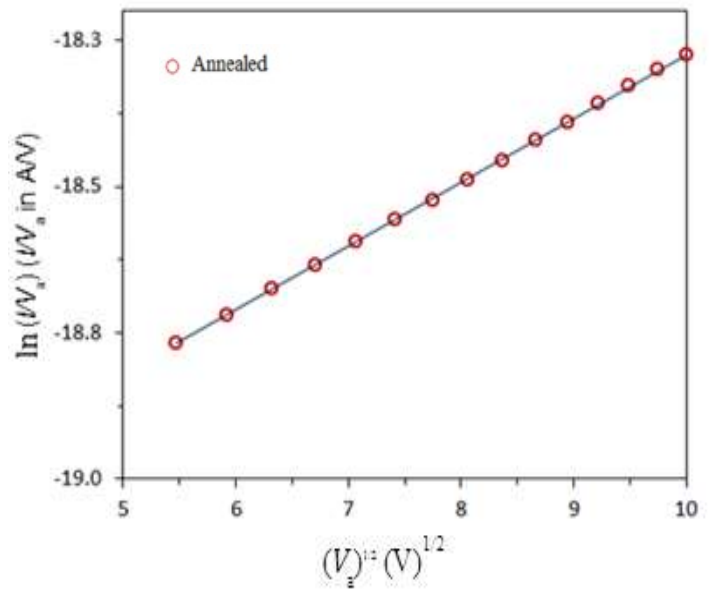

(b)

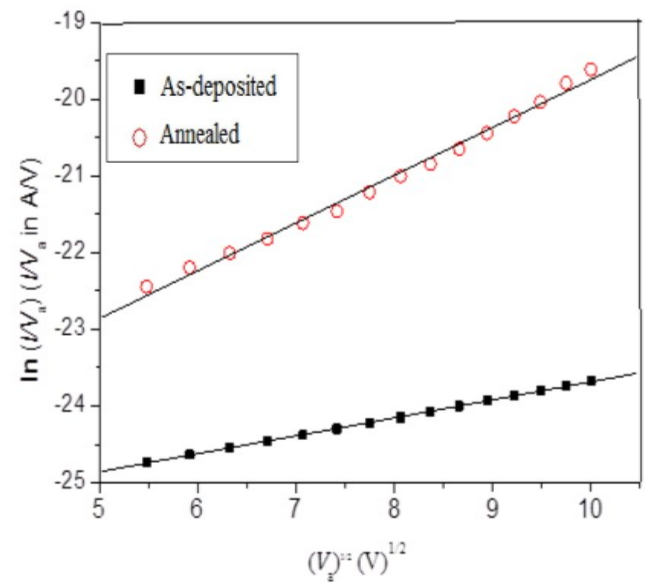

(c)

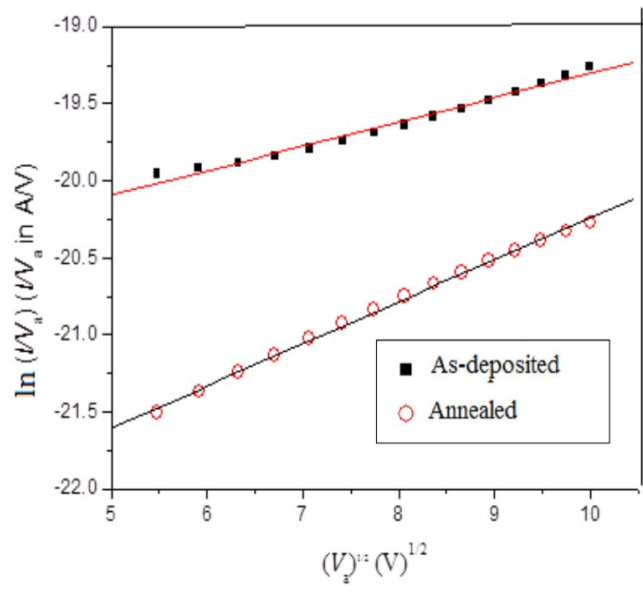

Figure 6: $\quad \ln \left(I / V_{\mathrm{a}}\right)$ versus square root of voltage in the range of $30 \mathrm{~V} \leq V_{\mathrm{a}} \leq 100 \mathrm{~V}$ for (a) annealed films compound 1, as-deposited and annealed compounds (b) 2 and (c) 3. 
(a)

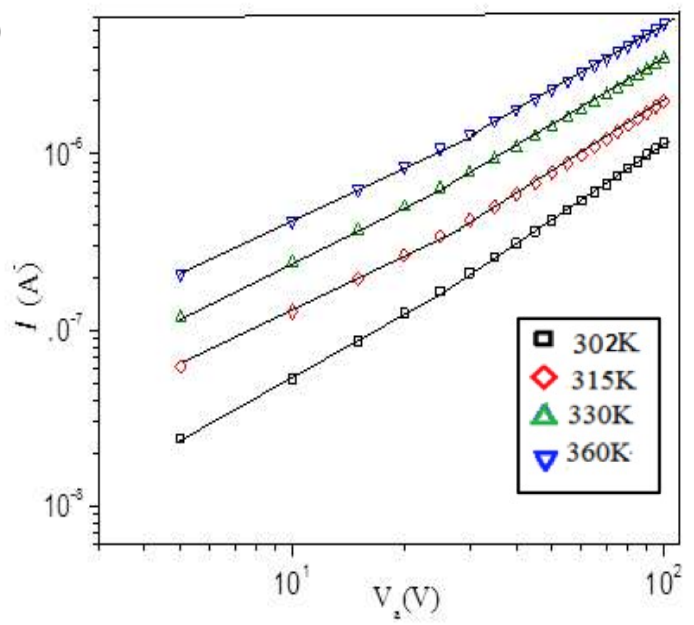

(b)

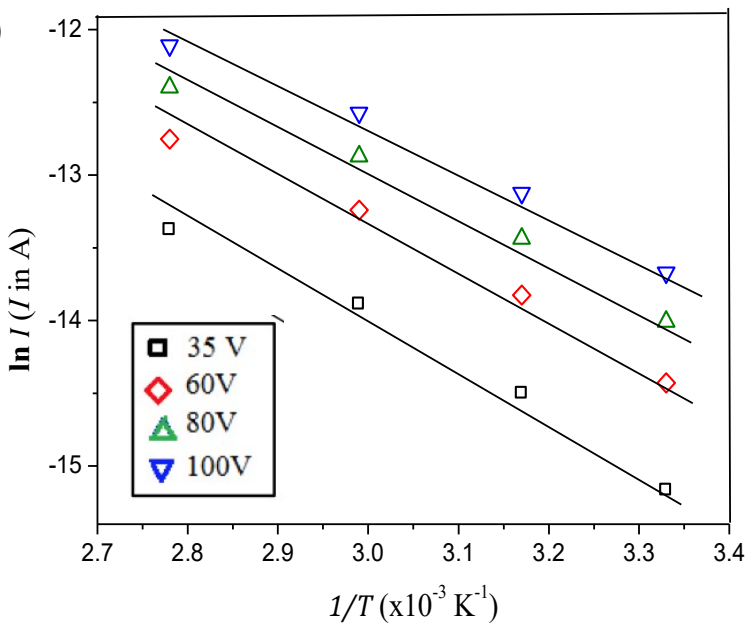

(c)

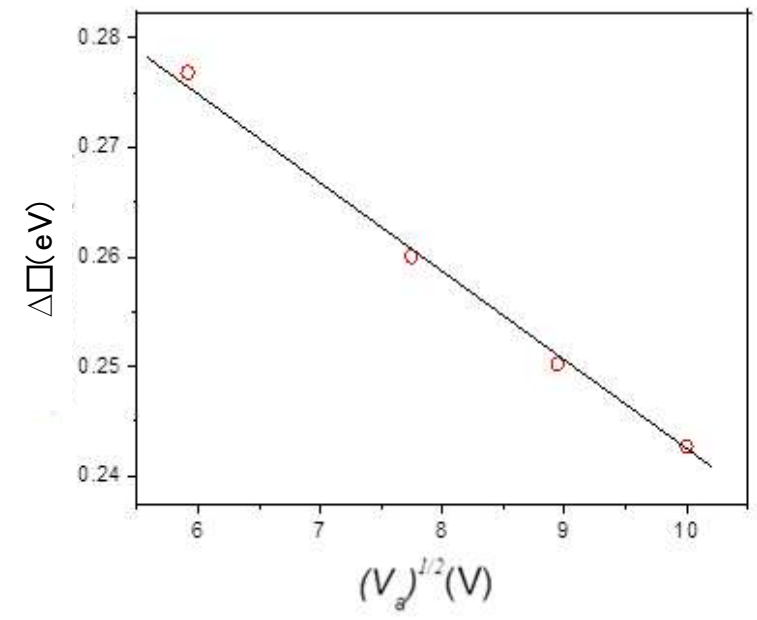

Figure 6: (a) Current-voltage characteristics for compound $\mathbf{1}$ at different temperature in the range of $302 \mathrm{~K}-360 \mathrm{~K}$ for annealed film, (b) logarithm of current versus temperature inverse at different voltages at different temperature in the range of temperature $302 \mathrm{~K}-360 \mathrm{~K}$, (c) $\Delta E$ versus square root of voltage plot for as-deposited film of compound $\mathbf{1}$. 

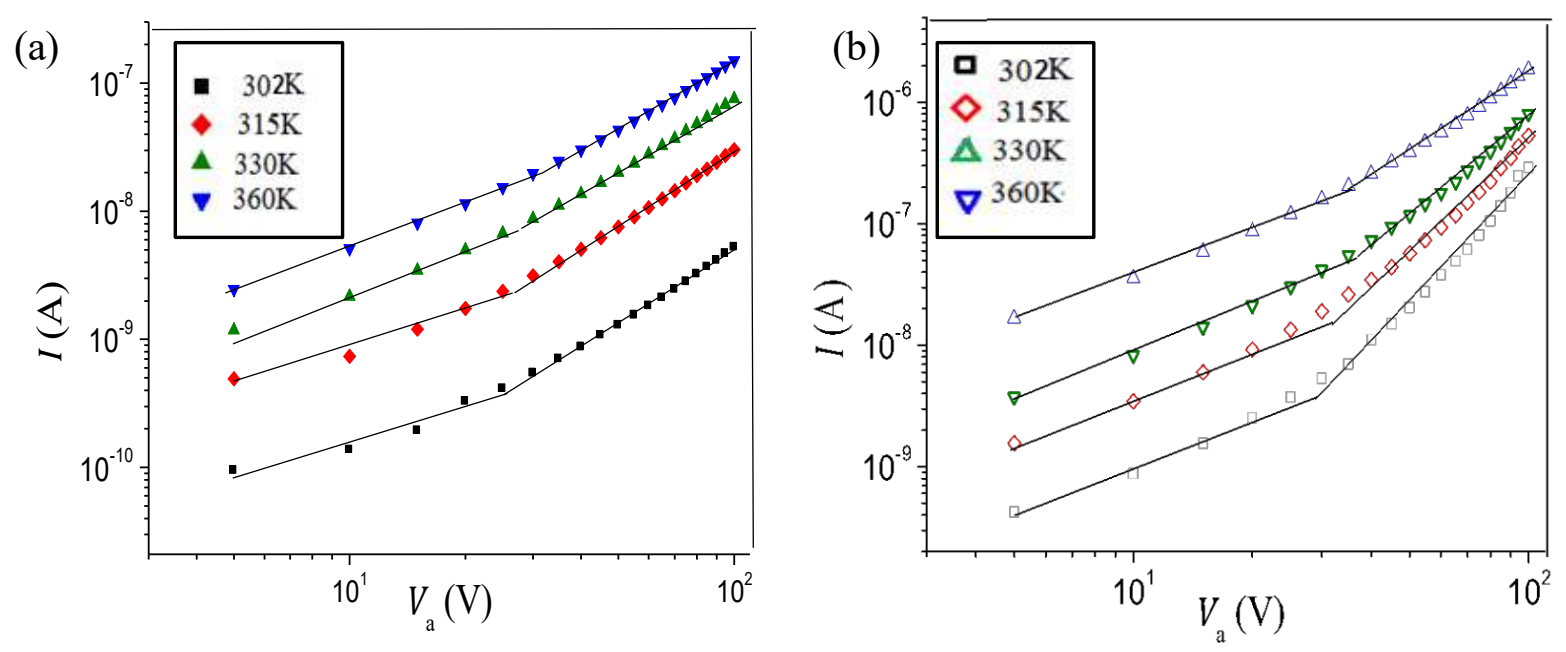

(c)

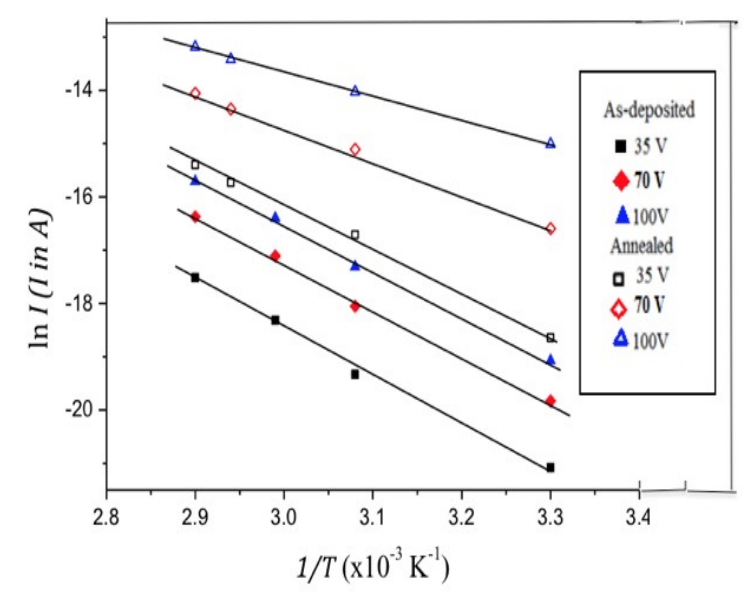

(d)

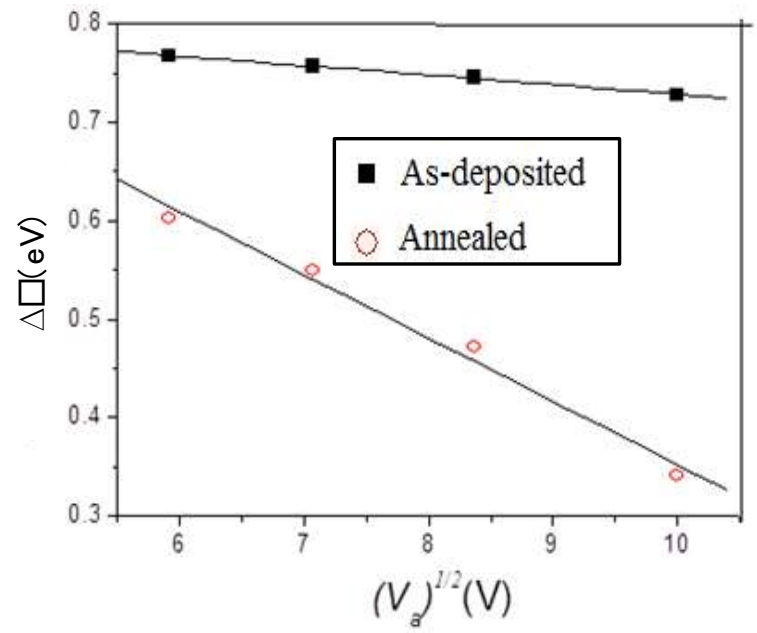

Figure 8: (a) Current-voltage characteristics at different temperature in the range of $302 \mathrm{~K}-360 \mathrm{~K}$ for (a) as-deposited and (b) annealed film of compound 2, (c) Logarithm of current versus temperature inverse at different voltages, (d) $\Delta E$ versus square root of voltage plot for as-deposited and annealed films of compound $\mathbf{2}$ 

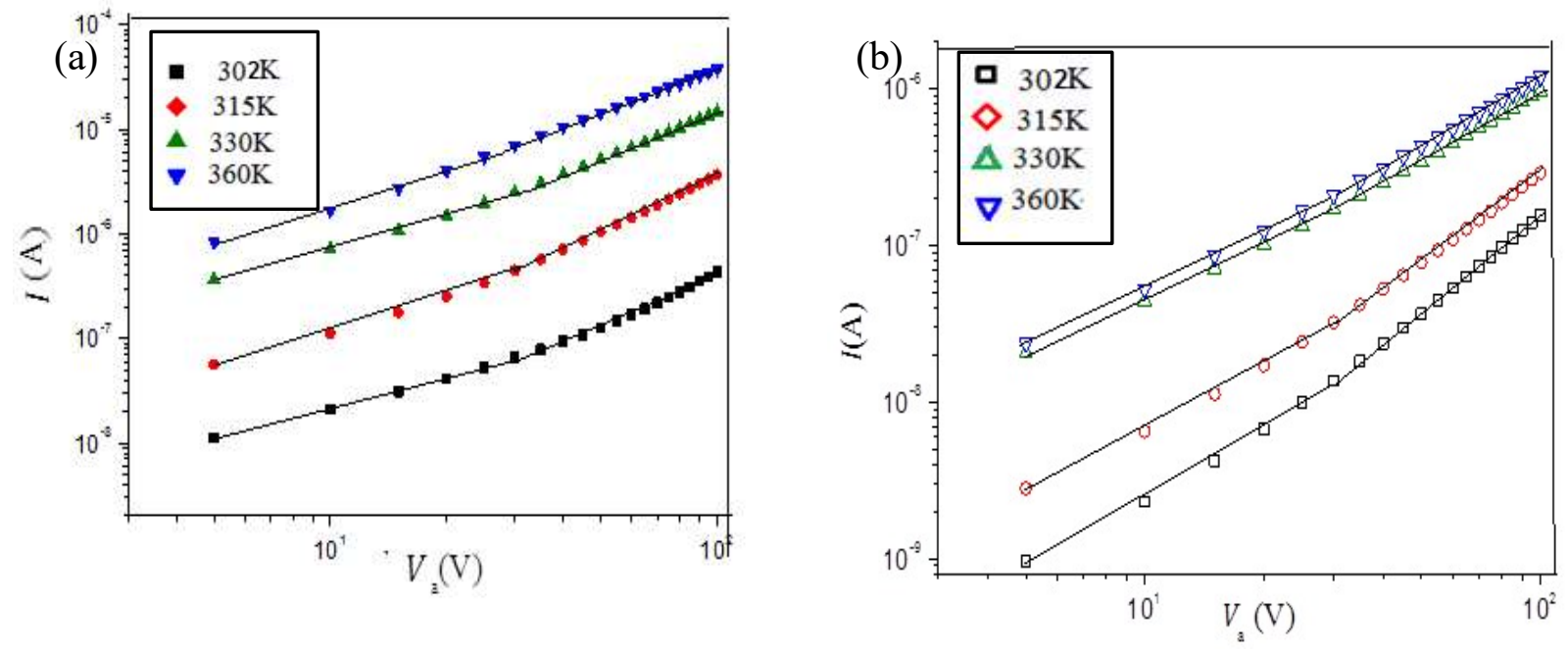

(c)
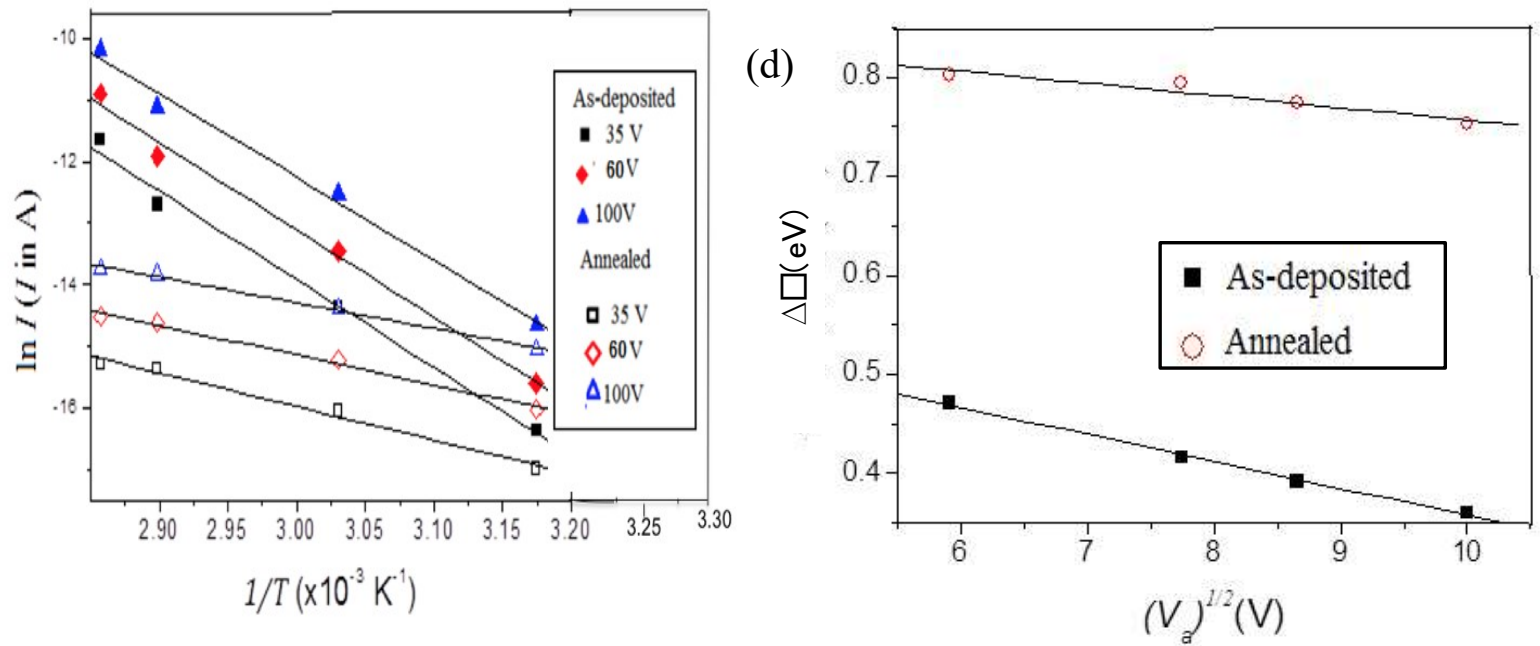

Figure 9: (a) Current-voltage characteristics at different temperature in the range of $302 \mathrm{~K}-360 \mathrm{~K}$ for (a) as-deposited and (b) annealed film of compound 3, (c) Logarithm of current versus temperature inverse at different, (d) $\Delta E$ versus square root of voltage plot for asdeposited and annealed films of compound 3 . 